\title{
Anxiety and Emotional-Behavioral Problems of Adolescents in China: Evidence for A Serial Mediation Model of Alexithymia and Dependency
}

Lijuan Liang ( $\sim$ lianglijuan_2005@163.com )

Hainan Medical University https://orcid.org/0000-0002-1081-0520

Wei Zhu

Hainan Medical University

Juan Yang

Hainan Medical University

Fei Wang

China Medical University

Research article

Keywords: Anxiety, Emotion-behavior problems, Adolescents, Dependence, Alexithymia

Posted Date: July 9th, 2020

DOl: https://doi.org/10.21203/rs.3.rs-40681/v1

License: (c) (1) This work is licensed under a Creative Commons Attribution 4.0 International License.

Read Full License

Version of Record: A version of this preprint was published at Psychology, Health \& Medicine on November 21st, 2021. See the published version at https://doi.org/10.1080/13548506.2021.2005249. 


\section{Abstract}

Background: High prevalence of emotional and behavioral problems among Chinese adolescence has been reported. This study seeks to investigate the mediating effect of alexithymia and dependency on anxiety and emotional-behavioral problems among adolescents. The study focused a serial mediation model of alexithymia and dependency adolescents from Haikou, China.

Methods: The study population included 519 adolescents. The assessments included the completion of standardized scales such as the Multidimensional Anxiety Scale (MASC), the Toronto Alexithymia Scale (TAS-20), the Depressive Experiences Questionnaire (DEQ), the Strengths and Difficulties Questionnaire (SDQ). Independent-sample t-tests, bivariate correlation, and serial mediation analyses were performed using SPSS23.0.

Results: Bivariate analyses revealed that anxiety, emotional-behavioral problem, alexithymia, and dependency were positively correlated. Alexithymia and dependency play a significant role in mediating the effect of multidimensional anxiety on emotional-behavioral problems. The effects of the three mediating paths were $69.86 \%, 17.81 \%$ and $12.33 \%$ for paths 1,2 and 3 respectively.

Conclusions: Anxiety and emotional-behavioral problems mediate the relationship between alexithymia and dependency.

\section{Background}

Adolescence is one of the most rapid phases of human development between childhood and adulthood. According to the World Health Organization (WHO), an adolescent is defined as any person between the age of 10 and 19 years[1].Adolescents are in a period of transition involving physical, psychological and mental health development. Related research shows that adolescents suffer from emotional-behavioral problems[2-3].The Strengths and Difficulties Questionnaire (SDQ) has been globally used to assess emotional and behavioral problems in children and adolescents[2-3]. Conduct problems in adolescents are a major public health problem due to their association with high rates of substance and alcohol abuse and criminal activity [4-5]. Adolescents with hyperactivity problem had more emotional and behavioral problems than adolescents of the healthy group, even emotion problem was associated with the severity of symptoms of hyperactivity problem[6-7]. Related research showed that late adolescent subjects with hyperactivity-problem comorbidity emotion problems [8]. Negative peer relationships have also been significantly associated with internalizing and psychological problems, such as emotional problems [9].

Anxiety disorders are the most prevalent mental health problems affecting about $20 \%$ of adolescents[10]. Comorbidities associated with anxiety and attention disorders are common mental disorders affecting about $25 \%$ of adolescents [16]. However, compared with an attention disorder, adolescents with anxiety comorbidity disorder showed deficits in executive function and cognitive function [16-17]. Other studies show that anxiety has a positive influence on behavioral problems. For example, individuals with high 
trait anxiety have been shown to perform better than those with low trait anxiety [12]. The Multidimensional Anxiety Scale for Children can be used to predict anxiety symptoms in adolescents since it has a high degree of reliability and validity for psychology measurements [14]. However, whether anxiety symptoms can be used to predict emotional-behavioral problems during adolescents development remains controversial[11].

Maladaptive personality traits are some of the important factors influencing the development of emotional-behavioral problems. Studies have revealed that subjects with personality disorders are more likely to have emotional-behavioral problems[15]. Other studies on the psychopathology of adolescent emotional-behavioral problems have indicated that personality traits are important moderators of emotional-behavioral problems hence adolescents with more maladaptive personality traits exhibit more conduct problems[13]. Several studies have revealed that emotional and behavioral problems are closely associated with personality characteristics that modulate the occurrence and development of emotionalbehavioral problems[18-19].

According to the Blatt model, mature personality is related to good interpersonal relationships and harmonious self-consciousness development[20].Dependency which is characterized by serious problems with interpersonal relationships is the basis of a psychopathic personality style associated with a sense of loneliness, weakness, helplessness, and fear of abandonment. The Depressive Experiences Questionnaire (DEQ) has not only good reliability and validity for the study of depression but also personality and general psychopathology. Self-criticism is significantly associated with depressive symptoms in patients with clinical depression while anxiety level is associated with dependency[21-22].

Alexithymia is described as the inability to identify, describe, and communicate emotions with others[23]. According to the alexithymia-stress hypothesis, alexithymia may increase anxiety in adolescents and affect the stress response. Adolescents with emotional and behavioral problems are more likely to develop alexithymia[24-26].

Therefore, this study on the mediating effects of dependency and alexithymia on anxiety and emotionalbehavioral problems among adolescents is important to provide an understanding of the psychological mechanism of these problems.

\section{Methods}

\subsection{Participants}

A total of 519 adolescents completed the questionnaires. The participants age ranged from 13 to 18 years $(M=16.02 ; S D=0.849)$. Participants with missing data such as age or gender were excluded from the study. Therefore, a total of 510 (251 males and 259 females) participants data was considered for the study. Students from the urban and rural areas participated in the study and accounted for $49.41 \%$ and $50.59 \%$ respectively. 
The study was approved by the Ethics Committee of Hainan Medical University. Participation was voluntary and signed parental informed consent was required. All questionnaires were administered in the classroom and required approximately 30 minutes to complete. The questionnaires were administered at different times to at least four subjects in every session. The class teacher was present to ensure that all the students were cooperative.

\subsection{Measures}

\section{Emotion-behavior problems}

The Strengths and Difficulties Questionnaire (SDQ) was downloaded from the SDQ official website (http://www.sdqinfo.com). SDQ has been globally used to screen for emotional and behavioral problems in adolescents [27-28]. The SDQ-C included 25 items distributed across five distinct subscales: emotional problems, conduct problems, hyperactivity, peer problems, and prosocial behaviors. Each subscale contained five items, each of which asked participants to report the degree to which a particular statement was true. Responses were in a Likert-type format with three options ( $0=$ "Not true", $1=$ "Somewhat true", 2 = "Certainly true"). Therefore, the score on each subscale ranged from 0 to 10 points. The Cronbach's alpha coefficient score for the questionnaire was 0.927 and each of the subscales was greater than $0.5[31]$. Since this study mainly focused on emotional and behavioral problems, prosocial behaviors were excluded.

\section{Anxiety}

The Multidimensional Anxiety Scale (MASC) is a self-report questionnaire assessing youth anxiety symptoms. It consists of 39 items and contains four main subscales: physical symptoms, social anxiety, separation anxiety/panic, and harm avoidance. The scale has demonstrated favorable psychometric properties in previous studies and the Cronbach's coefficient score for the questionnaire was 0.89[29-30]. Respondents separately rated each of the 39 items using a four-point scale anchored with the response options: "never true about me" (score 0 ), "rarely true about me" (=1), "sometimes true about me" (=2) and "often true about me" (=3).

\section{Dependency}

The Depressive Experiences Questionnaire (DEQ) is a 66-item self-report measure that yields scores on three scales: dependency, self-criticism, and efficacy. The DEQ items describe non-symptomatic experiences commonly reported by individuals and the Cronbach's coefficient score for the questionnaire was 0.89 [32]. This study chose the dependency factor since it contains primarily externally directed items which are concerned with feelings of helplessness and weakness, fears of being abandoned, and wishes to be cared for, loved, and protected. The responses were scored on a 7-point Likert scale, ranging from 1 = strongly disagree to 7 = strongly agree.

\section{Alexithymia}


The Toronto Alexithymia Scale (TAS-20) was used to assess alexithymia which is a self-report measure comprised of 20 items rated using a 5 -point Likert scale whereby $1=$ strongly disagree and $5=$ strongly agree[33]. The TAS-20 measures three dimensions: Difficulty Identifying Feelings (DIF), Difficulty Describing Feelings (DDF), and Externally-Oriented Thinking (EOT). TAS-20 remains the most commonly used measure of alexithymia [34]. Previous researches have reported psychometric properties of TAS-20 for adolescents [35-36].

\subsection{Statistical analysis}

Data entry and documentation were performed using Epidata. SPSS23.0 was used for descriptive and correlation analysis. The serial mediation analysis was performed using the Hayes' SPSS macro program PROCESS.

Descriptive statistics were computed for the major variables. Independent-sample t-tests were used to compare the normal and clinical sample emotional-behavioral problems. Cohen's convention was used to evaluate effect sizes. Cohen's $d$ values of $0.20,0.50$, and 0.80 were indicative of small, medium, and large effects, respectively[37]. Pearson correlation analysis examined the linear associations between anxiety, dependency, alexithymia and emotional; and behavioral problems among Chinese adolescents.

A script of the SPSS PROCESS macro program developed by Hayes[38] was used to test the mediation effects of multidimensional anxiety on emotional-behavioral problems, as well as the serial-mediated mediating effects of dependency and alexithymia among Chinese adolescents. Using the percentile method, the $95 \%$ bootstrap confidence intervals from 5000 bootstraps were calculated.

\section{Results}

\subsection{Collinear analysis}

The variance inflation factor (VIF) which is the reciprocal of the tolerance was used as the collinearity diagnostic index. The findings revealed that the VIFs of the MASC, DEQ, and TAS were less than 3 (1.31,1.40 and 1.41, respectively). High correlation and collinearity among variables was not an issue.

\subsection{Descriptive statistics}

The emotional-behavioral problems were classified into three types (normal, borderline and clinical). The findings revealed that the clinical samples had significantly greater multidimensional anxiety, alexithymia, and dependency (Table 1). No significant difference was reported between the normal and clinical groups for peer problems. 
Table 1

Comparison of Multidimensional Anxiety, Alexithymia and Dependency in Adolescents with Normal and Clinical Emotional-Behavioral Problems

\begin{tabular}{|c|c|c|c|c|c|c|}
\hline & norma & & clinical & & & \\
\hline Variables & Mean & SD & Mean & SD & $\mathbf{t}$ & Cohen's \\
\hline \multicolumn{7}{|l|}{ Emotion problem } \\
\hline Multidimensional Anxiety & .84 & .30 & 1.24 & .31 & 13.31 ** & 1.31 \\
\hline Alexithymia & 2.72 & .52 & 3.21 & .43 & $10.50^{* *}$ & 1.03 \\
\hline Dependency & 3.63 & .69 & 4.18 & .78 & $7.86^{\star \star}$ & 3.62 \\
\hline \multicolumn{7}{|l|}{ Conduct problrm } \\
\hline Multidimensional Anxiety & .84 & .36 & 1.13 & .33 & $9.66 * \star$ & 0.84 \\
\hline Alexithymia & 2.73 & .56 & 3.05 & .47 & $7.63^{* *}$ & 0.62 \\
\hline Dependency & 3.40 & .67 & 4.15 & .73 & $5.80 * \star$ & 1.07 \\
\hline \multicolumn{7}{|l|}{ Hyper problrem } \\
\hline Multidimensional Anxiety & .92 & .34 & 1.22 & .39 & $6.19 * \star$ & 0.82 \\
\hline Alexithymia & 2.81 & .48 & 3.26 & .44 & $6.73^{\star \star}$ & 0.97 \\
\hline Dependency & 3.68 & .70 & 4.38 & .88 & $6.68^{* *}$ & 0.87 \\
\hline${ }^{*} p<0.05,{ }^{* *} p<0.01$ & & & & & & \\
\hline
\end{tabular}

\subsection{Correlations among the main variables}

Pearson's correlation analysis (Table 2) demonstrated that all the variables had a statistically significant relationship $(p<.001)$. Specifically, emotional-behavioral problems were positively correlated with multidimensional anxiety $(r=0.41, p<0.01)$, alexithymia $(r=0.48, p<0.01)$, and the dependency $(r=0.55$, $p<0.01)$. Concerning the emotional and behavioral problem, alexithymia $(r=0.48)$ and dependency $(0.55)$ were also positively correlated. 
Table 2

Means, standard deviations, and intercorrelations of measures of main variables

\begin{tabular}{|c|c|c|c|c|c|c|c|c|}
\hline & Mean & SD & Min. & Max. & 1 & 2 & 3 & 4 \\
\hline 1.Multidimensional Anxiety & 1.02 & 0.35 & 0 & 3 & - & & & \\
\hline 2.Alexithymia & 2.95 & 0.51 & 1 & 5 & $.42^{\star \star}$ & - & & \\
\hline 3.dependency & 3.91 & 0.75 & 1 & 7 & $.56^{\star \star}$ & $.49 * \star$ & - & \\
\hline 4.emotion-behavior problem & 0.72 & 0.23 & 0 & 3 & $.41^{\star \star}$ & $.48 * \star$ & $.55^{\star \star}$ & - \\
\hline
\end{tabular}

\subsection{Model analysis}

The results of serial mediation model analysis and mediation effect test are shown in Table 3. The results showed that the total effect of multidimensional anxiety on emotion-behavior problems was statistically significant $(\beta=0.36, t=14.01, p \otimes 0.001)$ and the direct effect was also significant $(\beta=0.21, t=8.26 \square p \square$ $0.01)$. The multidimensional anxiety predicted alexithymia $(\beta=0.58, t=9.16, p \otimes 0.001)$, alexithymia significantly and positively predict emotional-behavioral problems $(\beta=0.07, t=8.28, p \otimes 0.001)$. This means that alexithymia plays a mediating role in the effect of multidimensional anxiety on emotionalbehavioral problems. The multidimensional anxiety predicted dependency $(\beta=0.93 \square t=6.93 \llbracket p \nabla 0.001)$, and dependency predicted emotional-behavioral problems $(\beta=0.10, t=3.96, p \otimes 0.001)$. Therefore, dependency plays a mediating role in multidimensional anxiety effects on emotional-behavioral problems. Alexithymia significantly predicted dependency $(\beta=0.51 \square t=7.87 \square p \nabla 0.001)$. Therefore, alexithymia and dependency play a serial-mediated role in the multidimensional anxiety effect on emotional-behavioral problems. 
Table 3

Analysis of serial mediation model

\begin{tabular}{|c|c|c|c|c|c|c|}
\hline \multicolumn{2}{|l|}{ Regression Equation } & \multicolumn{3}{|c|}{ Equation Fitting Index } & \multirow{2}{*}{$\begin{array}{l}\text { coefficient } \\
\beta\end{array}$} & \multirow{2}{*}{$\begin{array}{l}\text { significance } \\
\text { t }\end{array}$} \\
\hline Dependent Variable & Independent Variable & $\mathbf{R}$ & $\mathrm{R}^{2}$ & $\mathbf{F}$ & & \\
\hline \multirow[t]{2}{*}{ Alexithymia } & & 0.42 & 0.18 & $23.73^{\star \star}$ & & \\
\hline & $\begin{array}{l}\text { Multidimensional } \\
\text { Anxiety }\end{array}$ & & & & 0.58 & $9.16^{\star \star}$ \\
\hline \multirow[t]{3}{*}{ Dependency } & & 0.55 & 0.30 & $37.72^{\star \star}$ & & \\
\hline & $\begin{array}{l}\text { Multidimensional } \\
\text { Anxiety }\end{array}$ & & & & 0.64 & $6.93^{\star \star}$ \\
\hline & Alexithymia & & & & 0.51 & $7.87 \star \star$ \\
\hline \multirow{4}{*}{$\begin{array}{l}\text { Emotion-behavior } \\
\text { problem }\end{array}$} & & 0.69 & 0.47 & $64.44 * \star$ & & \\
\hline & $\begin{array}{l}\text { Multidimensional } \\
\text { Anxiety }\end{array}$ & & & & 0.21 & $8.26 * \star$ \\
\hline & Alexithymia & & & & 0.07 & $8.28 * \star$ \\
\hline & Dependency & & & & 0.10 & $3.96 * \star$ \\
\hline \multirow{2}{*}{$\begin{array}{l}\text { Emotion-behavior } \\
\text { problem }\end{array}$} & & .57 & 0.32 & $51.09 \star \star$ & & \\
\hline & $\begin{array}{l}\text { Multidimensional } \\
\text { Anxiety }\end{array}$ & & & & 0.36 & $14.01^{\star *}$ \\
\hline${ }^{\star} \mathrm{p}<0.05,{ }^{* \star} \mathrm{p}<0.01$ & & & & & & \\
\hline
\end{tabular}

The results of the analysis of the mediating effects are shown in Table 4 . The analysis showed that the 95\% confidence intervals for alexithymia and dependency did not include zero, which indicated that the two played a significant mediating role in the effect of multidimensional anxiety on emotional-behavioral problems. The intermediate effect was 0.144 which accounted for $39.04 \%$ of the total effect $(0.360)$. The effects of the three mediating paths were $69.86 \%, 17.81 \%$, and $12.33 \%$, for paths 1,2 and 3 respectively. The serial mediation model is shown in Fig. 1. 
Table 4

Total effect, direct effect and indirect effect

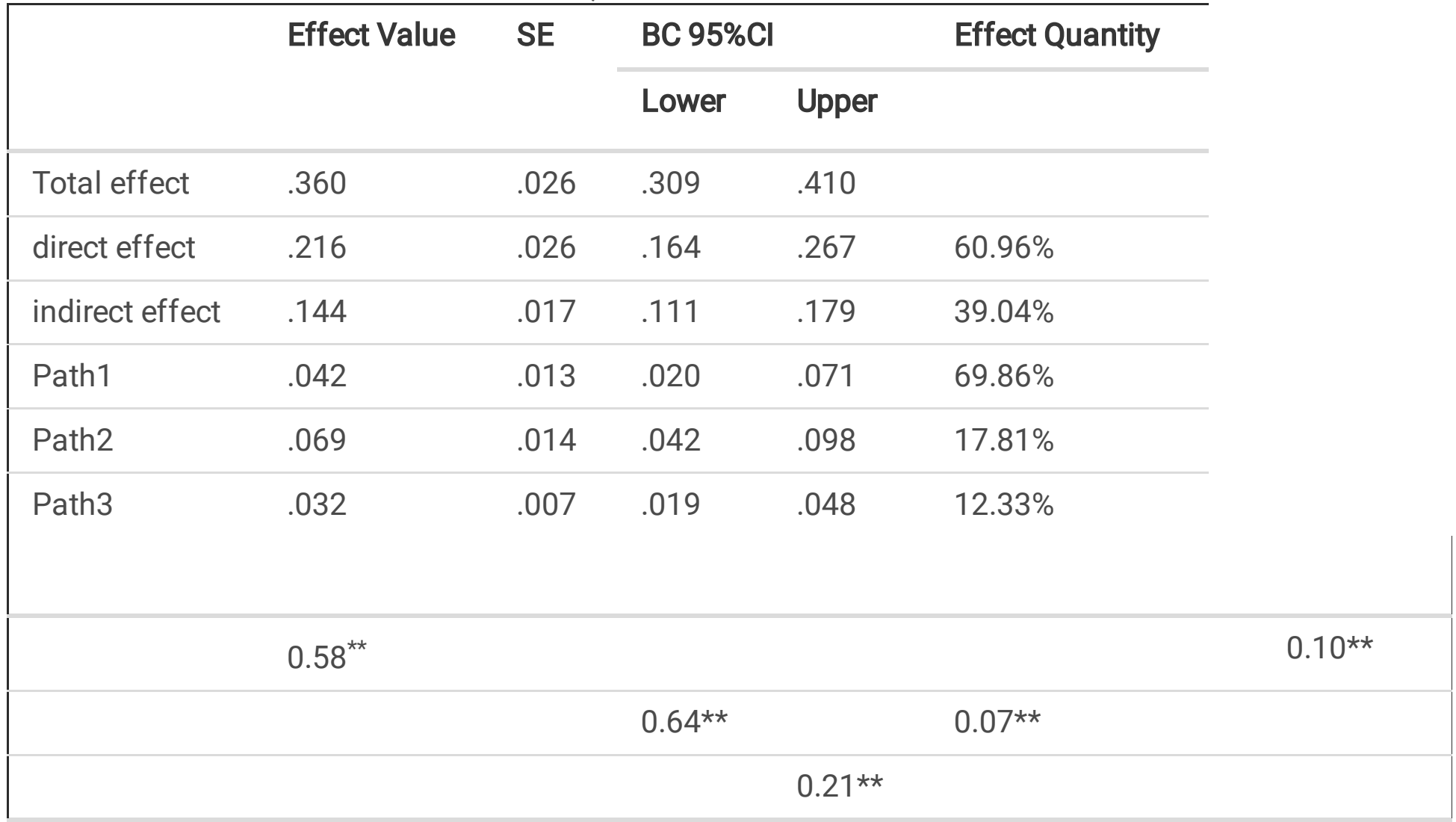

${ }^{*} \mathrm{p}<0.05,{ }^{* *} \mathrm{p}<0.01$

Path1 $=$ specific indirect effect through alexithymia;Path2 = specific indirect effect through dependency; $P$ ath $3=$ specific indirect effect through alexithymia and dependency

\section{Discussion}

This investigated the role of anxiety as a risk factor in increasing of emotional-behavioral problems among adolescents. Also, the study examined the serial mediation path from anxiety to emotionalbehavioral problems through dependency and alexithymia.

In this study, $79.63 \%$ of the adolescents showed emotional-behavioral problems when compared with the normal group. The clinical samples showed more emotional and behavioral problems. These findings were consistent with previous studies where participants with emotional-behavioral disorders showed increased multidimensional anxiety levels [40], alexithymia [41-42], and dependence[43-44]. However, significant differences were not reported for peer problems in both the normal and clinical samples.

This study explored the relationship between multidimensional anxiety, alexithymia, dependence and emotional-behavioral problems in adolescents. Consistent with previous studies, adolescents with anxiety symptoms have shown increased emotional-behavioral problems [45-48], and multidimensional anxiety. Negative personalities are positive predictors of adolescent emotional-behavioral problems [22]. 
Adolescents with anxiety often exhibit comorbid symptoms of emotional-behavioral problems [54-56]. Immature personality factors are also risk factors for emotional-behavioral problems in adolescents. Alexithymia is conceptualized as a personality trait that is normally distributed in the population and is associated with an increased risk of psychopathology [49]. In this study, alexithymia was significantly associated with poor interpersonal relationships. Also, high alexithymia subjects are reported to show increased interpersonal relationship problems, attachment insecurity, avoidant behavior and suicidal behavior [50-52]. Adolescents with alexithymia exhibit some impairment in emotional expression and emotional recognition and increased introversion. Also, they show distorted cognition and inhibited behavior during interpersonal relationships, which may further exacerbate emotional-behavioral problems. Dependency is an immature, non-mutually satisfying personality trait. Previous studies have reported that the abnormal group with psychological behavior show increased dependence [53]. Therefore, alexithymia and dependency personalities may be risk factors for adolescents' emotionalbehavioral problems.

Additional research shows that anxiety not only directly affects adolescents' emotional-behavioral problems but also indirectly affects them through the mediating effects of dependency and alexithymia. The mediating effect includes three paths: (1) the mediating path through alexithymia; (2) the mediating path through dependency; and (3) the chain mediating path through dependency and alexithymia.

These study findings revealed that alexithymia and dependent personality are factors that play an important mediating role in the relationship between anxiety and emotional-behavioral problems in adolescents, and these findings were consistent with previous research [57]. A negative personality trait is one of the main mediating variables of emotional-behavioral problems and can partly explain abnormal emotional-behavioral problems [61]. Inappropriate personality traits impair the ability to regulate adolescents' emotions, and this could lead to increased emotional-behavioral problems. Recent studies have reported an association between alexithymia with immature ego defense styles, which implies a relatively primitive way of dealing with emotional problems [58]. Previous studies also indicate that anxiety is interrelated with alexithymia [59-60], and participants with emotional-behavioral problems showed more dependency personality traits [43].

This study investigates the relationship among adolescent anxiety, alexithymia, dependency and emotional-behavioral problems to provide evidence for preventive interventions for adolescents at risk of emotional-behavioral problems. Some factors are considered to increase the prevalence of emotionalbehavioral problems in adolescents including parental and individual factors [62-63]. Mature personality trait also reduces emotional-behavioral problems.

\section{Limitation And Future Direction}

The sample size in this research was relatively small, and further research will require expanding the sample size to ensure that the study is more representative. This study was mainly a cross-sectional study lacking the intervention and follow-up research, hence the dynamic process among the variables is 
a possible future research direction. The research method was a self-report, which may be subjective. Future research should consider experimental methods to explore the mechanism between anxiety and emotional-behavioral problems.

\section{Conclusion}

Alexithymia and dependency were found to play a role in the chain mediating effects on anxiety and emotional-behavioral problems in adolescents.

\section{Ethics approval and consent to participate}

This study was approved by the ethics committee of the Hainan Medical University. All participants and their guardians gave written informed consent before the study.

\section{Declarations}

\section{Ethics approval and consent to participate}

This study was approved by the ethics committee of the Hainan Medical University. All participants and their guardians gave written informed consent before the study.

\section{Consent for publication}

Not applicable.

\section{Availability of data and materials}

The datasets used during the current study are available from the corresponding author on reasonable request.

\section{Competing interests}

The authors declare no conflict of interest.

\section{Funding}

Not applicable.

\section{Authors' contributions}

Lijuan Liang managed the literature searches, participated in the collection and analysis of data and wrote the manuscript. Wei Zhu participated in collect and analysis of data. Juan Yang designed the study, participated in the collection and analysis of data. Fei Wang supervised the sample recruitment and provided suggestions. All co-authors have approved the final manuscript. 


\section{Acknowledgements}

We are indebted to all participants to attend our study. We also would like to thank Hengting Chen for their time to take part in collecting data.

None of the authors has a financial interest in the results of the study.

\section{References}

1. World Health Report. Retrieved July 7. 2018. from.. http://www.who.int/whr/2001/en/.

2. Ortuño SJ. Aritio SR,Fonseca PE.Mental health diffiffifficulties in children and adolescents: the study of the SDQ in the Spanish national health survey 2011-2012. J Psychiatr Res. 2018;259:236-42.

3. Rimvall $\mathrm{M}$, Elberling $\mathrm{H}$, Rask $\mathrm{CH}$. Predicting $\mathrm{ADHD}$ in school age when using the strengths and diffiffifficulties questionnaire in preschool age: a longitudinal general population study. Eur Child Adoles Psychiatr. 2014;23(11):1051-60.

4. Heron J, Maughan B, Dick DM, Kendler KS,Lewis G, Macleod J,et al.Conduct problem trajectories and alcohol use and misuse in mid to late adolescence.Drug and Alcohol Dependence.2013; 1:133(1):100-107.

5. Pardini DA, Byrd AL, Hawes SW, Docherty M. Unique Dispositional Precursors to Early-Onset Conduct Problems and Criminal Offending in Adulthood. Journal of the American Academy of Child Adolescent Psychiatry. 2018;57(8):583-92.

6. Klassen AF,Miller A,Fine S. Health-related quality of life in children and adolescents who have a diagnosis of attention-deficit/hyperactivity disorder.Pediatrics.2004; 114(5):541-547.

7. Yunhye, Oh. Yoon HJ,Kim JH,Joung YS.Trait Anxiety as a Mediator of the Association between Attention Deficit Hyperactivity Disorder Symptom Severity and Functional Impairment. Clin Psychopharmacol Neurosci. 2018;16(4):407-14.

8. Jarrett MA. Ollendick TH.A conceptual review of the comorbidity of attention-deficit/hyperactivity disorder and anxiety: Implications for future research and practice. Clin Psychol Rev. 2008;28(1):1266-80.

9. Li X, Luo X, Zheng R, Jin X,Mei L, Xie X,et al. The role of depressive symptoms, anxiety symptoms,and school functioning in the association between peer victimization and internet addiction: A moderated mediation model. J of Affective Disorders. 2019;256:125-31.

10. Costello EJ,Egger H,Angold A.The developmental epidemiology of anxiety disorders: phenomenology, prevalence, and comorbidity.Child \& Adolescent Psychiatric Clinic of North America. 2005; 14(4):631-48.

11. Fanti KA. Hellfeldt K, Olivier FC, Meehan A. Worried, sad, and breaking rules? Understanding the developmental interrelations among symptoms of anxiety, depression, and conduct problems during early childhood. Journal of Criminal Justice. 2019;62:23-8. 
12. Tong $L$, Shi HJ,Zhang Z, Yuan, Y,Xia ZJ,Jiang. XX,Xiong X.Mediating effect of anxiety and depression on the relationship between Attention-deficit/hyperactivity disorder symptoms and smoking/drinking. J Am Acad Child Adolesc Psychiatry. 2018;57(7):457-9.

13. Bloemsma JM1, Boer F, Arnold R, Banaschewski T. Faraone SV,Buitelaar JK,Sergeant JA,Rommelse $\mathrm{N}$, Oosterlaan J.Comorbid anxiety and neurocognitive dysfunctions in children with. ADHDEur Child Adolesc Psychiatry. 2013;22(4):225-34.

14. Wei C, Hoff A,Villabø MA,Peterman J, Kendall PC,Piacentini J,et al. Assessing anxiety in youth with the multidimensional anxiety scale for children. J Clin Child Adolesc Psychol. 2014;43(3):566-78.

15. Horowitz LM, Wilson KR, Turan B, Zolotsev P, Constantino MJ,Henderson L. How interpersonal motives clarify the meaning of interpersonal behavior: A revised circumplex model. Personality Social Psychology Review. 2006;10:67-86.

16. Gosch EA. Treating a Child With Anxiety and Attention-Deficit/Hyperactivity Disorder? Don't Rule Out Cognitive-Behavioral Therapy. J Clin Exp Neuropsychol. 2017;39(5):434-48.

17. Babinski DE, Neely K. Kunselman A,Waschbusch DA.Attention-deficit/hyperactivity disorder and callous-unemotional traits as moderators of conduct problems when examining impairment in emerging adults. Psychiatry Res. 2017;258:525-30.

18. Westen D, Gabbard G, Blagov P(2006). Back to the future: Personality structure as a context for psychopathology.2006; 335-384.

19. Eduardo FP Serafín, Mercedes LG. P,José M.Schizotypy, emotional-behavioural problems and personality disorder traits in a non-clinical adolescent population. Psychiatry Res. 2011;190(23):316-21.

20. Blatt A. Experiences of Depression. Theoretical, Research and Clinical Perspectives. Isr J Psychiatry Relat Sci. 2004;44(4):330-2.

21. Straccamore F, Ruggi S, Lingiardi V, Zanardi R,Vecchi S, Oasi OPersonality. Factors and Depressive Configurations. An Exploratory Study in an Italian Clinical Sample. Front Psychol. 2017;8:251.

22. Campos RC. Besser A,Blatt SJ.The Portuguese Version of the Depressive Experiences Questionnaire (DEQ): Results from a Validation Program in Clinical and non Clinical Samples. The Spanish Journal of Psychology. 2013;16(e103):1-13.

23. Sifneos PE.The prevalence of alexithymic characteristics in psy-chosomatic patient.Psychother psychosom.1973; 22:255-262.

24. Matrinez SF. Ato GM,Ortiz SB.Alexithymia-state or trait? [ J]. Spain J Psychol. 2003;6:51-9.

25. Thorberg FA, Young RMD,Lyvers M, Connor. JP,Feeney GFX.A psychometric comparison of the Toronto Alexithymia Scale (TAS-20) and the Observer Alexithymia Scale (OAS) in an alcoholdependent sample. Personality Individ Differ. 2010;49(2):119-23.

26. Emma K. Catherine S,KateT.Investigating alexithymia in autism: A systematic review and metaanalysis. European Psychiatry. 2019;55:80-9. 
27. Goodman R. Psychometric properties of the strengths and difficulties questionnaire. J Am Acad Child Adolesc Psychiatry. 2001;40:1337-45.

28. Yao S, Zhang C, Zhu X. XiaoJ,McWhinnie CM,Abela JRZ.Measuring Adolescent Psychopathology: Psychometric Properties of the Self-Report Strengths and Difficulties Questionnaire in a Sample of Chinese Adolescents.J Adolesc Health.5(1):55-62.

29. Baldwin JS. Dadds MR.Reliability and validity of parent and child versions of the Multidimensional Anxiety Scale for Children in community samples. Journal of the American Academy of Child \&Adolescent Psychiatry. 2007;46(2):252-60.

30. Wei C, Hoff A,Villabø MA,Peterman J, Kendall PC,Piacentini J,et al.Assessing Anxiety in Youth with the Multidimensional Anxiety Scale for Children (MASC).J Clin Child Adolesc Psychol. 2014; 43(4): 566-578.

31. Liang L, Yang J. Yao S.Measurement equivalence of the SDQ in Chinese Adolescents: A horizontal and longitudinal perspective. J Affect Disord. 2019;257:439-44.

32. Blatt SJ. Afflitti JP,Quinlan DM.Experiences of depression in normal young adults. J Abnorm Psychol. 1976;85:383-9.

33. Bagby RM, Parker JD, Taylor G. J.The twenty-item Toronto Alexithymia Scale-I. Item selection and cross-validation of the factor structure. J Psychosom Res. 1994;38:23-32.

34. Bagby RM,Taylor G,Parker JDA,Dickens SE.The development of the Toronto structured interview for Alexithymia: Item selection, factor structure,reliability, and concurrent validity.

35. 75

25

39

Psychotherapy and Psychosomatics.2006;75:25-39.

36. Taylor GJ. Bagby RM,Parker JDA.The 20-item Toronto Alexithymia Scale. IV. Reliability and factorial validity in different languages and cultures. J Psychosom Res. 2003;55:277-83.

37. Ling Y, Zeng Y, Yuan H, Zhong Y. Cross-cultural validation of the 20 -item Toronto Alexithymia Scale in Chinese adolescents. J Psychiatr Ment Health Nurs. 2016;23:179-87.

38. Smithson M. Shou Y.Moderator effects differ on alternative effect-size measures. Behav Res Methods. 2017;49(2):747-57.

39. Hayes AF. Introduction to Mediation, Moderation, and Conditional Process Analysis: a Regressionbased Approach. J Educ Meas. 2014;51(3):335-7.

40. Kovacs S. Sharp C.Criterion validity of the Strengths and Difficulties Questionnaire (SDQ) with inpatient adolescents. Psychiatry Res. 2014;219:651-7.

41. Stephen $\mathrm{H}$, Simon $\mathrm{CH}$. Toby T.The multidimensional anxiety scale for children: a further validation with Australian adolescents with and without ADHD. J Atten Disord. 2014;18(5):402-11.

42. Gawęda $t$. Krężołek M.Cognitive mechanisms of alexithymia in schizophrenia: Investigating the role of basic neurocognitive functioning and cognitive biases. Psychiatry Res. 2019;271:573-80. 
43. Moriguchi Y. Age and gender effect on alexithymia in large, Japanese community and clinical samples: a cross-validation study of the Toronto Alexithymia Scale (TAS-20). BioPsychoSocial Medicine. 2007;1(7):1-15.

44. Mattias D, Vanheule S, Groenvynck H, Verhaeghe P, Lebiger-Vogel J, Bogaerts S. Desmet.The Depressive Experiences Questionnaire. European Journal of Psychological Assessment. 2007;23(2):89-98.

45. Falgares G, De Santis S, Gullo S, Kopala-Sibley DC. Scrima F,Livi S.Psychometric Aspects of the Depressive Experiences Questionnaire: Implications for Clinical Assessment and Research. J Personality Assessment. 2018;100(2):207-18.

46. Moskowitz LJ, Walsh CE, Mulder E, McLaughlin DM, Hajcak G, Carr EG.et al. Intervention for Anxiety and Problem Behavior in Children with Autism Spectrum Disorder and Intellectual Disability. J of Autism Developmental Disorders. 2017;47:3930-48.

47. El-Guebaly N, Scott B. Patten. SB,Currie S.Epidemiological Associations between Gambling Behavior, Substance Use \& Mood and Anxiety Disorders. J Gambl Stud. 2016;22:275-87.

48. Biggs BK. Vernberg EM,Wu YP.Barzeva SA.Social Anxiety and Adolescents'Friendships: The Role of Social Withdrawal. The Journal of Early Adolescence. 2011;32(6):802-23.

49. Cohen JS, Kendall PC. Peer victimization among children and adolescents with anxiety disorders. Child Psychiatry Hum Dev. 2015;46(3):393-405.

50. Franz M, Popp K, Schaefer R, Sitte W, Schneider C, Hardt J, et al. Alexithymia in the German general populationSocial Psychiatry Psychiatric Epidemiology. 2008;43:54-62.

51. Vanheule S. Desmet M,Meganck R,Bogaerts S.Alexithymia and interpersonal problems. J Clin Psychol. 2007;63(1):109-17.

52. Spitzer C, Siebel-Jurges U. Barnow S,Grabe HJ,Freyberger HJ.Alexithymia and interpersonal problems. Psychother Psychosom. 2005;74(4):240-6.

53. Huang KC, Tzeng DS, Lin CH, Chung WCInterpersonal-Psychological. Theory, Alexithymia, and Personality Predict Suicide Ideation among Maladjusted Soldiers in Taiwan.2017;47(5):603-611.

54. O'Garro-Moore JK. Adams AM,Abramson LY,Alloy LB.Anxiety comorbidity in bipolar spectrum disorders: the mediational role of perfectionism in prospective depressive symptoms. J Affect Disord. 2015;174:180-7.

55. Rebar AL, Stanton R, Rosenbaum S. Comorbidity of depression and anxiety in exercise research. Lancet Psychiatry. 2017;4(7):519.

56. Graham N, Smith DJ. Comorbidity of depression and anxiety disorders in patients with hypertension. J Hypertens. 2016;34(3):397-8.

57. Yen CF, Chou WJ, Liu TL. Yang P,Hu HF.The association of Internet addiction symptoms with anxiety,depression and self-esteem among adolescents with attention-deficit/hyperactivity disorder. Compr Psychiatry. 2014;55(7):1601-8. 
58. Fonseca-Pedrero E, Lemos-Giráldez S. Paino M,Muñiz J.Schizotypy, emotional-behavioural problems and personality disorder traits in a non-clinical adolescent population. Psychiatry Res. 2011;190(23):316-21.

59. Parker JD, Taylor GJ, Bagby RM. Alexithymia: relationship with ego defense and coping styles. Compr Psychiatry.998;39:91-98.

60. Tutkun H. Savas HA,Zoroglu SS,Esgi K,Herken H,Tiryaki N.Relationship between alexithymia, dissociation and anxiety in psychiatric outpatients from Turkey. Isr J Psychiatry Relat Sci. 2004;41:118-24.

61. Sayar K, Kose S. The relationship between alexithymia and dissociation in an adolescent sample. Bull Clin Psychopharmacol. 2003;13:167-73.

62. O'Garro-Moore JK,Adams AM,Abramson LY,Alloy LB..Anxiety comorbidity in bipolar spectrum disorders: the mediational role of perfectionism in prospective depressive symptoms, J Affect Disord,2015, 180-7.

63. Aboobaker S, Jangam KV, Sagar KJV, Amaresha AC. Jose A.Predictors of emotional and behavioral problems among Indian adolescents: A clinic-based study. Asian J Psychiatr. 2019 Jan;39:104-9.

64. Arslan G. Psychological maltreatment, emotional and behavioral problems in adolescents: The mediating role of resilience and self-esteem. Child Abuse Neglect. 2016;52:200-9.

\section{Figures}

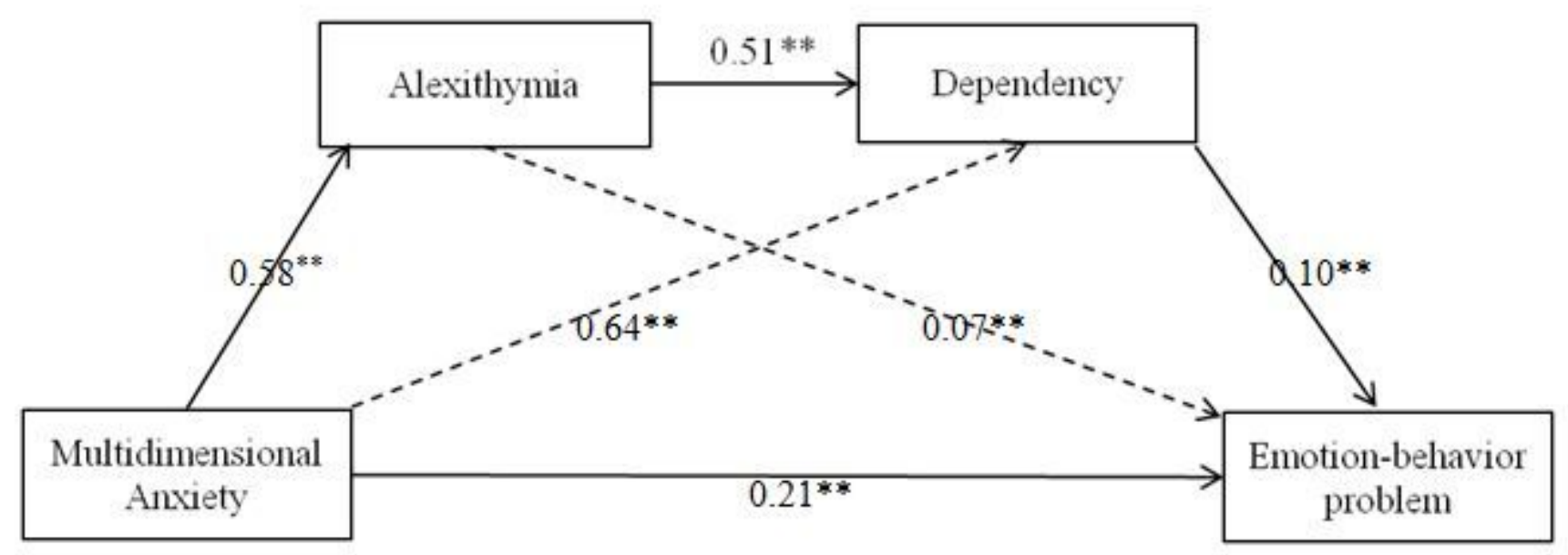

$* \mathrm{p}<0.05, * * \mathrm{p}<0.01$

\section{Figure 1}

Illustration of an (in)direct effects model for serial mediation utilizing alexithymia and dependency 